\title{
"Fue bonita la solidaridad entre mujeres": género, resistencia, y prisión política en Chile durante la dictadura
}

\begin{abstract}
Resumen: En este artículo ocuparemos la teoría de género para analizar las historias orales de presas políticas en Chile durante la dictadura. En particular, nos interesa la manera en que las mujeres podían ocupar estrategias generizadas de resistencia y solidaridad, aunque reconocemos que estas mismas estrategias podían volverse insuficientes, ya que la misma naturaleza extrema de la tortura y la prisión política terminó promoviendo el instinto de sobrevivir a todo costo. Finalmente, concluimos que las memorias de las ex presas políticas han sido profundamente influenciadas, en muchos casos, por contactos posteriores con el feminismo. Palabras claves: Género; prisión política; resistencia; memoria; feminismo.
\end{abstract}

(c) $\odot$ Esta obra tem licença Creative Commons.

\section{"Abriendo el 'abanico de color' de la resistencia femenina: prisión política, tortura y mujeres en Chile"}

Patricia Herrera fue detenida el 27 de junio de 1974, tenía 20 años y era estudiante universitaria. Pasó por los centros clandestinos de la detención Londres 38, Cuatro Álamos y Tres Álamos en Santiago, lugares donde fue brutalmente torturada, y posteriormente fue forzada a salir al exilio. El 10 de diciembre de 2010, Herrera, con la organización feminista Humanas, presentó una querella por tortura sexual, el primero de su tipo en Chile. En esa ocasión sostuvo: "no sólo es conmigo, es con las mujeres que pasaron las torturas y que hoy son detenidas desaparecidas, por lo que para mí es un compromiso de por vida"; su abogada, Camila Maturana agregó: "Es necesario visibilizar esta problemática que ha estado oculta. Esto es muy delicado. La forma de violencia que vivieron ellas es extremadamente cruel y 


\begin{abstract}
1 "Presentan querella por violencia sexual como tortura en dictadura," Radio Bío-Bío, 7 de diciembre de 2010, http://www.biobiochile.cl 2010/12/07/presentan-querellapor-violencia-sexual-como-torturaen-dictadura.shtml

${ }^{2}$ El uso de "sobrevivientes", y no "víctimas", es intencional y parte de la perspectiva feminista de este trabajo. De modo general, podríamos decir que ocupar variaciones del verbo "sobrevivir" pone el acento en la resiliencia de las mujeres y su capacidad de "elaborar" los traumas del pasado, tal como plantea Dominick LaCapra. No obstante, esta terminología no borra el hecho que también hubo momentos de victimización profunda para las presas políticas. Esta tensión entre "victimización" y "agencia" ha sido más explorada en la literatura sobre la violencia "doméstica", pero también es aplicable a nuestro análisis, ya que también estamos tratando un tipo de violencia de género y el tema de sobrevivientes mujeres. Ver: Natalie SOKOLOFF e Ida DUPONT, 2005, p.3.
\end{abstract}

${ }^{3}$ Pilar CALVEIRO, 2001 [1998], p. 131. personal. No es fácil hacer lo que Patricia hace hoy día, es una mujer muy valiente". ' Recientemente, el 28 de mayo de 2014, Nieves Ayress, Alejandra Holzapfel, Soledad Castillo y Nora Brito - con el apoyo de la Corporación Parque de la Paz Villa Grimaldi - presentaron otra querella, esta vez por violencia sexual política, que también fue acogida por tribunales. Estas nuevas querellas y la atención mediática que han generado demuestran claramente que ya estamos hablando, y cada día más, del tema de la tortura sexual en Chile. No obstante, los textos sobre la tortura ejercida en contra de las mujeres han tendido a ser mayoritariamente descriptivos, una denuncia. Aquí rescataremos en algo el tono de denuncia que tienen los testimonios de las mujeres sobrevivientes ${ }^{2}$ de la tortura en Chile, particularmente sus perspectivas en cuanto la manera en que esa tortura fue generizada y sexualizada, como también presentaremos un argumento coherente y constante con respecto a las variadas estrategias, individuales y colectivas, que las mujeres utilizaron a la hora de resistir la tortura, incluso en las situaciones más límites. No obstante, es también importante recordar, a la misma vez, que no todas las "resistencias" eran siempre del mismo grado, ni tampoco que todas las mujeres necesariamente "resistieron". También hubo instancias de negociación, cooptación, y abierta colaboración; como señala Pilar Calveiro: "...la oposición entre el héroe y el traidor es una oposición falsa, más que por injusta, porque sencillamente resulta insuficiente para describir la complejidad del problema. No hay aquí una gama de grises sino todo un abanico de color que incluye muchos otros tonos." ${ }^{3}$ De esta manera, exploraremos las complejas, y a veces contradictorias, memorias de las mujeres sobrevivientes de la prisión política en Chile durante la dictadura.

Ahora, antes de trabajar las narrativas de las mujeres sobrevivientes es necesario aclarar algunos de las premisas teóricas que guían nuestro análisis, como también revisar el estado de arte que existe en torno a las temáticas de la "nueva izquierda", la prisión política, y el género. En primer lugar, es menester entrar a definir con más precisión qué queremos decir a la hora de hablar de "resistencia" dentro del contexto de la prisión política. De manera más general, es común asociar el término "resistencia" con actos de carácter popular de lucha, en gran parte debido a la influencia marxista y gramsciana, donde existen políticas y culturas de "dominación" (hegemónicas; de élites) y "resistencia" (contra hegemónicas; del pueblo/lo subalterno). Esta tendencia tiene raíces, además, en las luchas antifascistas en Europa durante la Segunda Guerra Mundial, que se llamaban derechamente "La Resistencia" en países como Francia e Italia. Durante los años 60 y 70 -y dentro de 
${ }^{4}$ Frantz FANON, 1983 [1961], p. 17-18. un contexto mundial donde se fue rápidamente expandiendo distintas formas de guerra de guerrillas y luchas anticoloniales - "resistencia" también solía ser ocupada como eufemismo de "violencia justa". Así una serie de pensadores de izquierda-muchos de los cuales también fueron militantes activos, como Frantz Fanon, Che Guevara, Regis Debray, Jean-Paul Sartre y AntonioNegri - inspiraban una generación entera en diferentes continentes con la posibilidad de doblarle la mano a la dominación hegemónica capitalista e imperialista a través de la resistencia, o "poder", popular. En las palabras de Fanon: "En la descolonización hay, pues, exigencia de un replanteamiento integral de la situación colonial. Su definición puede encontrarse, si se quiere describirla con precisión, en la frase bien conocida: "Ios últimos serán los primeros". La descolonización es la comprobación de esa frase. Por eso, en el plano de la rescripción, toda descolonización es un logro. Expuesta en su desnudez, la descolonización permite adivinar a través de todos sus poros, balas sangrientas, cuchillos sangrientos. Porque si los últimos deben ser los primeros, no puede ser sino tras un afrontamiento decisivo y a muerte de los dos protagonistas. Esa voluntad afirmada de hacer pasar a los últimos a la cabeza de la fila, de hacerlos subir a un ritmo (demasiado rápido, dicen algunos) los famosos escalones que definen a una sociedad organizada, no puede triunfar sino cuando se colocan en la balanza todos los medios incluida, por supuesto, la violencia." 4

Durante los años 70 y 80 en muchos países latinoamericanos también se hacía referencia a una "resistencia" organizada a los regímenes autoritarios. Pero en el contexto de la persecución masiva y el autoritarismo, estas resistencias asumían diferentes formas y se canalizaban a través de diferentes discursos y prácticas. Mientras algunos grupos, como el Frente Patriótico Manuel Rodríguez (FPMR) en Chile seguían una línea similar a los grupos armados de los años 60 y $70-$ proponiendo una insurrección popular y un fin a la dictadura vía las armas , esto no fue la norma. De hecho, en este período es más común asociar la "resistencia" a las dictaduras con las tácticas de la no-violencia activa y los movimientos sociales, particularmente los grupos de dere-chos humanos. De esta manera, conceptos como la "ciuda-danía activa" y la "participación desde abajo" (desde los grassroots como se decía en inglés) empezaban a informar nuestros entendimientos de lo que significaba "resistencia". Esto se fue cruzando, además, con discursos de grupos de mujeres, tanto feministas como pobladoras y familiares de personas tocadas por violaciones de los derechos humanos, que levantaban el tema de una cultura de la "vida", en contraste en la cultura de la "muerte" de la dictadura. Así se fue 
${ }^{5}$ Elizabeth JANEWAY, 1980; James SCOIT, 1986

${ }^{6}$ Steve STERN, 1995.

7 John DINGES, 2004: Danie FEIERSTEIN, 2009; Greg GRANDIN, 2007; Peter KORNBLUH, 2003. formando un concepto de "resistencia" que tenía mucho más que ver con la no-violencia de figuras como Martin Luther King Jr. o Gandhi, y menos con figuras del período previo que justificaban el uso de la violencia. En el contexto de la prisión política, además, las tácticas de resistencia no-violenta también fueron frecuentemente empleadas, tales como las huelgas de hambre o la negación de cumplir con reglamentos básicos de la cotidianidad carcelaria. Fue en este momento histórico de los años 80 , además, cuando se empezaba a investigar empíricamente con más detalle las resistencias históricas de los campesinos y obreros, particularmente desde la teoría del "poder" o "las armas" de los débiles, como lo plantean Elizabeth Janeway y James Scott, respectivamente. ${ }^{5}$ Esto, acompañado por un giro hacia los estudios subalternos y campesinos en la Historia Social, tuvo como resultado un rescate de las múltiples y diversas maneras en que los/as campesinos/as mostraban su disentimiento y ejercían la "infrapolítica", para utilizar un término de Scott, en sus resistencias cotidianas. El estudio de Steve Stern sobre la violencia de género y las mujeres en México durante el S.XIX también plantea formas generizadas de esta infrapolítica, tales como la magia negra, la propagación de los rumores, y la apelación a los "pactos patriarcales"; todas éstas estrategias implementadas por las mujeres a la hora de prevenir y resistir la violencia contra ellas. ${ }^{6}$

No obstante, a la hora de entender la resistencia en el contexto de la prisión política tenemos que volcar nuestra mirada teórica hacia otros referentes, principalmente por el hecho que estamos hablando de resistencias dentro de espacios que son, de por sí, fundamentalmente jerárquicos, autoritarios, coercitivos y violentos (como el centro de tortura o la cárcel). Aunque puede parecer un cierto tipo de "sentido común" a estas alturas, vale recordar que dentro del esquema del régimen autoritario - que asigna un rol privilegiado a la función de la persecución y la prisión política-existen ciertos sujetos marcados por el Estado como "no deseables" y fuertemente perseguidos. En el contexto de las dictaduras latinoamericanas, esta persecución se canalizó principalmente por la Doctrina de Seguridad Nacional que tildó de "enemigos internos" a ciudadanos/as asociados/as con la izquierda (o sospechados de ser así). ${ }^{7}$ La implementación de proyectos de "policidio", como lo llama Steve Stern, donde se buscó "extirpar" el cáncer marxista del cuerpo socio-político dentro de las Américas y en el contexto de la Guerra Fría, significó un fuerte giro hacia el autoritarismo y el terrorismo de Estado. Así millones de militantes y simpatizantes de izquierda fueron secuestrados, torturados, exonerados o exiliados y cientos de miles de estos no aparecieron nunca más, formando parte de las largas listas de ejecutados/as y desaparecidos/as. 
${ }^{8}$ Juan CORRADI, et. al., 1992; Jean FRANCO, 2013.

${ }^{9}$ Naomi KLEIN, 2007.

10 Olga GRAU et al., 1997; Julieta KIRKWOOD, 1986; Teresa VALDÉS, 1987; María Elena VALENZUELA, 1987.

11 Bruno BETTLEHEIM, 1943; Raúl HILBERG, 1961.
Sin embargo, y como otros académicos como Juan Corradi, Manuel Antonio Garretón y Jean Franco han dejado en claro, el secuestro, la tortura y la desaparición forzada de ciertos dirigentes políticos puntuales tenía un doble efecto: por un lado, promovía la desarticulación de la organización socio-político y ponía fin a un proyecto político, pero, por otro lado, también infundía, de manera masiva, el terror y el miedo. ${ }^{8}$ Por tanto, es importante recordar que los centros de tortura no sólo funcionaban como lugares aislados donde se aplicaban ciertos tipos de apremios físicos y psicológicos, sino que también fueron los engranajes más profundos del proyecto de cambio socio-político que se buscaba implantar. Esto fue el modelo neoliberal a la usanza del "American way of life" de Estados Unidos, individualista y consumista - que Naomi Klein identifica como el principal objetivo del "shock" perpetrado por las dictaduras. ${ }^{9}$ Es importante no dejar de lado este aspecto socio-económico ni mirar a la tortura sólo como una práctica aislada y propia de las dictaduras latinoamericanas. En el caso de Chile, este "shock" también fue reflejado en el deseo de "volver hacia atrás" y proteger "los valores" hetero-patriarcales de Dios, familia y patria, ya que se buscaba "re-fundar" la nación a través de la "buena crianza" de los niños dentro de la familia "tradicional" y cristiana. ${ }^{10}$

La bibliografía sobre la represión autoritaria y la prisión política en Latinoamérica es enorme y no pretendemos pasarla en su enteridad en este pequeño texto. Pero es relevante notar dos tendencias grandes que marcaron la producción de esta literatura en sus diversas fases. Por un lado, es común encontrar, dentro de la bibliografía sobre la violencia política latinoamericana, referencias frecuentes al Holocausto y los campos de concentración. Tal vez por lo mismo, la mayoría de las primeras representaciones del terrorismo de Estado de las dictaduras latinoamericanas, tales como el libro del periodista judíoargentino Jacobo Timerman, Preso sin nombre, celda sin número, de 1982, la película La noche de los lápices de Héctor Olivera, estrenada en 1986, o el informe de la Conadep, Nunca Más, publicado por primera vez en 1984, destacaban, de manera explícita e implícita, las semejanzas entre los campos de concentración nazi y los centros clandestinos de detención (CCD) en Argentina, como también las similitudes entre la estrategia de Nachtund nebel (Noche y niebla) en Alemania y los secuestros y desapariciones forzadas del Cono Sur. Tal vez en menor medida, pero no menos importante, también hubo una incorporación superficial de algunos estereotipos del Holocausto que iban a ser reclamados posteriormente por historiadores/as especialistas: por un lado, la idea, muy refutada actualmente, de la víctima judía como inherentemente "pasiva", según los textos fundacionales de los estudios del Holocausto de Bruno Bettelheim y Raúl Hilberg; ${ }^{11}$ y por otro 
12 Sonja HEDGEPETH y Rochelle SAIDEL, 2010; Janet JACOBS, 2010.

${ }^{13}$ Emilio CRENZEL, 2008; Hugo VEZZETTI, 2002

${ }^{14}$ Hillary HINER, 2009.

${ }^{15}$ Ximena BUNSTER, 1985. lado, la tendencia de excluir la variable de género a la hora de pensar la violencia, los campos de concentración y la exterminación. ${ }^{12}$

A la misma vez, hay otra faceta importante dentro de la literatura sobre las dictaduras latinoamericanas: un énfasis pronunciado en el fenómeno de los detenidos desaparecidos y sus familiares, tal vez por el mismo éxito y presencia mediática de estos últimos como protagonistas de partidos políticos y grupos de derechos humanos. Algunos académicos, como Emilio Crenzel y Hugo Vezzetti, han propuesto que estos factores contribuyeron a la reificación de las "víctimas inocentes", y el blanqueamiento de la militancia política de muchos de los presos políticos y desaparecidos en las narrativas de los informes de las comisiones de la verdad y los juicios en Argentina. ${ }^{13}$ La falta de referencia a los grupos armados $y$ partidos políticos también tendía a ocultar la naturaleza colectiva de la experiencia de prisión política y las maneras en que los presos/as políticos/as podían resistir y ser solidarios/ as dentro de las condiciones físicas más abismantes. Finalmente, los informes de las comisiones de la verdad no sólo "blanqueaban" el factor político, sino también el factor de género, ya que en las narrativas se refieren a hombres como las principales víctimas o a lo universal de "las víctimas"; en ambos casos se excluye, de entrada, las experiencias de las mujeres presas y el análisis de género. ${ }^{14}$ Todo lo señalado hasta ahora significó un silenciamiento relativamente grande a la hora de tomar en cuenta la narrativa de las presas políticas y sus experiencias dentro de los centros de tortura hasta bien adentrada la década de los 90.

Con la excepción del texto de Ximena Bunster, "Surviving Beyond Fear", publicado en Estados Unidos en 1985, no hubo muchos textos académicos que trataron, directamente, el tema de la tortura sexual y las presas políticas chilenas durante los años $80 .{ }^{15}$ Muchas mujeres entrevistadas aluden al miedo de hablar durante este período, tanto por el factor preponderante de que Chile seguía en dictadura, como también por otras razones, como el hecho de sentir pudor, de no querer "achacar" a la familia o la pareja, o de no sentirse psicológicamente preparada todavía como para enfrentar memorias tan dolorosas. No obstante, hubo algunas mujeres valiosas, particularmente en el exilio, que igual prestaban testimonio sobre la tortura que habían padecido en Chile en diferentes foros de los derechos humanos, como los de la ONU, organizaciones internacionales de derechos humanos como Amnistía o Human Rights Watch, o partidos políicos o sindicatos solidarios con ciertos partidos chilenos, presos políticos o exiliados. Muchas mujeres ex presas políticas que estaban en el extranjero también empezaban a explorar el mundo del feminismo, donde encontraban discursos y 
${ }^{16}$ Edda GAVIOLA, et al., 1994.

17 GAVIOLA, et al., p. 10. prácticas muy útiles a la hora de trabajar la violencia contra la mujer y la resistencia de las mujeres.

En 1994, y ya en plena transición, se publicó un libro que incluía testimonios de mujeres activistas de derechos humanos, feministas y sobrevivientes de la tortura, Una Historia Necesaria: Mujeres en Chile: 1973-1990, de Edda Gaviola, Eliana Largo y Sandra Palestro, que fue bien fundacional en la historiografía feminista y bien innovador en su metodología, ya que es uno de los primeros que se hace desde la Historia Oral (se hicieron más de 50 entrevistas con mujeres en varias regiones de Chile) y la Historia Reciente, y donde además se construyó su narrativa desde las subjetividades y sensibilidades de las mismas investigadoras. ${ }^{16}$ Como señalan las autoras al cerrar la Presentación su libro: "Hemos reconstituido una historia hecha de silencios, de memorias fragmentadas, acalladas desde fuera y desde dentro. Para nosotras, hacer este trabajo significó mil veces un dolor que no podemos explicitar aquí. Muchas veces tuvimos que parar... quizás sea más sano vivir el daño que hacer como que no existió. Sólo el contento que nos producía des-cubrir lo que entre todas habíamos hecho nos impulsaba a seguir, a pesar de nosotras mismas." 17 Esta estrategia feminista de "visibilizar" las memorias fragmentadas de mujeres sobrevivientes y dejar un fuerte testimonio de "denuncia", tenía fuertes raíces en los grupos feministas de concientización que tipificaban los años 80 , como también en la publicación tan exitosa del testimonio de la guatemalteca maya-quiché Rigoberta Menchú, ganadora del Premio Nobel de la Paz en 1992.

Para fines de los años 90 , salió otro libro bien importante dentro de la bibliografía sobre presos políticos, aunque no tuviera una perspectiva explícita de género: Poder $y$ desaparición, de Pilar Calveiro. Este libro fue extremadamente importante en el desarrollo de estudios sobre los/as presos/as políticos/as y la tortura en Latinoamérica, ya que documentó, con mucho detalle, el ciclo del secuestro, tortura y "traslado" (desaparición forzada) que caracterizaba la prisión política en Argentina, como también la manera en que se iban configurando el poder y la identidad dentro de los "chupaderos". Que Calveiro misma fue sobreviviente - aunque no escribiera desde el "yo" y utilizara un lenguaje más bien académico igual ayuda a darle una gran cuota de autenticidad como también le permite, según mi evaluación, entrar en temáticas típicamente consideradas como "tabú" a la hora de hablar de la presión políica. Un tema que ya vimos en la introducción, fue la complejidad de ser "héroe" o "traidor", lo cual Calveiro deconstruye en su totalidad y plantea reemplazar con un "abanico de colores" para representar los comportamientos, actitudes y acciones de los/as presos/as dentro de las condiciones límites de un centro de tortura. También aporta 
${ }^{18}$ CALVEIRO, 2001 [1998], p. 160.

${ }^{19}$ Leonor ARFUCH 2013; Elizabeth JELIN, 2001; Nelly RICHARD, 1998, 1999, 2007.

${ }^{20}$ Victoria ALVAREZ, 2000; Andrea ANDÚJAR et al., 2005, 2009; Edelmira CARRILLO, et al., 2012; Débora D'ANTONIO, 201 1; Marta DIANA, 1997; Lessie Jo FRAZIER Y Deborah COHEN, 2003 GIANORDOLI-NASCIMENTO et al., 2012; Paola MARTINEZ, 2009 ; Alejandra OBERTI et al., 2012 Alejandra OBERTI, 2013, Joana PEDRO et al., 2011; Amelinha TELES y Rosalina LEITE, 2013 Tamara VIDAURRÁZAGA, 2007, Cristina WOLFF, 2011

${ }^{21}$ WOLFF, 2011 , p. 33. un valioso análisis de la razón por la cual no hubo una participación más activa de los/as sobrevivientes en las construcciones de la memoria post-dictatorial: "El sobreviviente siente que él vivió mientras que otros, la mayoría, murieron. Sabe que no permaneció vivo porque fuera mejor y, en muchos casos, tiende a pensar que precisamente los mejores murieron (...) [Y] Si aquél que se fuga de un campo de concentración es sospechoso, el que sobrevive lo es muchísimo más. Poco importa su resistencia, la habilidad que haya desplegado para engañar o burlar a sus captores, las solidaridades de las que haya sido capaz. La sociedad quiere entender por qué está vivo y él no puede explicarlo, de manera que casi automáticamente se lo condena a la exclusión y su vida se convierte en la prueba misma de su culpabilidad, cualquiera que ésta sea."18

Después de este libro de Calveiro y al entrar al siglo XXI, hubo un cierto tipo de "boom" en los estudios de la memoria y la historia oral en Latinoamérica, tal vez mejor encapsulado en el proyecto grande del SSRC sobre memoria en el Cono Sur, liderado por Elizabeth Jelin y Steve Stern. Este giro hacia la teorización de lo testimonial y la memoria, también tiene un componente fuerte de género, visto en las obras de la misma Jelin, Nelly Richard y Leonor Arfuch. ${ }^{19}$ A un nivel más empírico también hay cada vez más producción a nivel latinoamericano dedicada al análisis de género de los grupos de "nueva izquierda" de los años 60 y 70, como también al estudio de las mujeres en su paso posterior por la prisión política y el exilio. ${ }^{20}$ Dentro de mucha de esta literatura se pone énfasis en la manera en que los grupos de "nueva izquierda" mantuvieron valores profundamente masculinos y heteronormativos, como también la forma en que las mujeres dentro de los centros de tortura fueron castigadas por transgredir las normas heteropatriarcales de ser buenas madres y esposas. Además, como señala Cristina Wolff: "Nas memórias de muitas mulheres participantes da luta de esquerda armada no Cone Sul nos finais dos anos 1960 e início dos anos 1970, é muito claro um sentimento de amargura com relação às organizações das quais elas faziam parte. As acusações são muitas, e fortes: as mulheres raramente chegavam a postos de direção, tinham que estar a todo instante provando que eram confiáveis, corajosas e fortes, e elas tinham que se desligar de tudo o que representava sua feminilidade para serem levadas a sério. Além disso, a elas eram costumeiramente delegadas tarefas consideradas como secundárias." 21

En Chile las mujeres participaron ampliamente y de manera diversa dentro de los movimientos socio-políticos de los 70. Las mujeres de derecha, principalmente de clase media hacia arriba, participaron en grandes números en el

874 Estudos Feministas, Florianópolis, 23(3): 867-892, setembro-dezembro/2015 
22 Michele MATTELART, 1980; Margaret POWER, 2009.

${ }^{23}$ Gwynn THOMAS, 2011.

${ }^{24}$ Thomas KLUBOCK, 1998; Karin ROSEMBLATT, 2000; Heidi TINSMAN, 2002.

\footnotetext{
${ }^{25}$ Francesca MILLER, 1991
}

Poder Femenino ${ }^{22}$ como también en el Partido Demócrata Cristiano. Como señala Gwynn Thomas, este tipo de movilización política tendía a resaltar el lugar de la mujer como buena madre-esposa cristiana dentro de la familia para movilizarla como opositora al gobierno de la UP. ${ }^{23}$ Durante el período de Allende, las mujeres de izquierda tuvieron un rol en los partidos políticos, los grupos armados, las organizaciones de base en las poblaciones, los centros de madres, y los sindicatos de campesinos y obreros que apoyaban a la UP, aunque ese rol fue casi siempre enunciado y entendido desde el prisma de lo "femenino". Además, como la izquierda en Chile siempre puso, desde principios del siglo XX, un gran énfasis en la necesidad de conseguir un "sueldo familiar" $y$ proteger la mujer del trabajo - reasignándola al lugar "natural" del hogar y la crianza de los hijos - no hubo una conciencia de la manera en que las mujeres dentro de la casa también podían ser reprimidas, ni tampoco ningún análisis real del valor del trabajo no remunerado de las mujeres dentro del hogar. $^{24}$

No obstante, por otro lado, esta incapacidad de ver los cruces entre género y clase también fue bien común durante los años 70, y no sólo en Chile. Esto tendría como resultado que incluso dentro de los círculos más leales a la UP no hubo ningún cuestionamiento, o cuestionamientos sólo muy parciales y bien silenciados, del orden tradicional de la familia y el rol de la mujer dentro de esa familia. Por el contrario, las mujeres de izquierda hablaban de la liberación de la mujer dentro del proyecto socialista: la mujer y el hombre eran "complementarios", con roles específicos de género. La mujer debía aportar al socialismo, a través de su rol de buena madre - educando a futuras generaciones socialistas - y buena esposa - apoyando a su marido obrero en la casa. Lo que se está planteando aquí, claramente, es un rechazo hacia el feminismo de segunda ola que existía en el norte durante ese momento, considerado por muchos/as como "burgués" y "foráneo", justo cuando los imperativos culturales del momento tenían que ser "populares", nacionales y antiimperialistas. ${ }^{25}$ Por supuesto que hubo cambios culturales que se iniciaron en esta década para no volverse nunca más hacia atrás - la llegada de las pastillas anticonceptivas a Chile en 1966 y la correspondiente baja en el número de hijos/as por familia, la creciente minimización de la importancia de llegar virgen al matrimonio y la posibilidad, incluso, de formar pareja fuera del matrimonio, y la entrada cada vez más masiva de las mujeres a las universidades y el trabajo todos estos cambios siguieron firmemente de pie en las décadas después. Pero no debemos pasar por alto, tampoco, que seguía existiendo una corriente poderosa de conservadurismo en temas de género en Chile, promovida por el peso 
${ }^{26}$ Victor Hugo ROBLES, 2008.

27 Julie SHAYNE, 2004, p. 77.

${ }^{28}$ INFORME VALECH, Cap. VII, p. 486.

29 INFORME VALECH, Cap. VII, p. 485.

${ }^{30}$ INFORME VALECH, Cap. VII, p. 486. sociocultural combinado de la Iglesia Católica, la moralidad paternalista del Estado, y los valores burgueses de las familias "bien constituidas". Ni hablar de las mujeres lesbianas o trans, cuyas identidades fueron frecuentemente vividas, si es que podían ser vividas, con altos grados de clandestinidad por la violencia y la discriminación cotidiana que enfrentaban. ${ }^{26}$ En las palabras de la conocida socióloga feminista Teresa Valdés, "Lo que pasa con la UP hoy en día es que depende de cómo tú la miras. Desde la perspectiva de la UP, lo que les ofrecieron [a las mujeres] tuvo como resultado un aumento extraordinario en la participación femenina...No hubo una consciencia de género ni nada así. Pero sí hubo mucha participación de mujeres." 27 Por tanto, aunque las participación de las mujeres de izquierda en los movimientos socio-políticos tendía a ser rígidamente demarcada por los roles "apropiados de su sexo", igual hubo una participación importante en el proyecto socialista y existen numerosos ejemplos donde su participación informó e inclinó el balance de poder hacia una mayor igualdad entre los géneros. En un contexto de alta politización de la familia, la comunidad, y el campo, no debe sorprender que hubiese sido así, ya que las mujeres también jugaban roles que les asignaban grandes responsabilidades: velar por la casa, pero también por la educación y la salud de su comunidad.

Dentro de este contexto, las mujeres de izquierda que decidieron formar parte de los partidos políticos y los grupos armados de los años 70 son de un perfil diverso. En primer lugar, la gran mayoría de las mujeres de izquierda, si participaron en algún partido político, participaron en el Partido Socialista (PS), el Partido Comunista (PC) o el Movimiento de la Izquierda Revolucionaria (MIR). Según el Informe Valech, que nos puede dar una cierta idea de la participación políica delas mujeres al momento del golpe y durante la dictadura posterior, de las detenidas, 751 fueron del PC, 577 del PS, y 263 del MIR-FPMR, aunque tal vez lo que más llama la atención es que 442 mujeres sólo fueron "simpatizantes de izquierda" y 1.179 mujeres no tenían ninguna militancia política al momento de su detención. ${ }^{28}$ Las mujeres, al igual que los hombres, fueron relativamente jóvenes, de un universo de 3.399 mujeres, $2.063(60,7 \%)$ tenían 30 años o menos al momento de su detención. ${ }^{29} \mathrm{Y}$ por lo mismo no nos debe sorprender que casi un cuarto de ellas $(22,45 \%)$ fueran estudiantes de colegio o universidad al momento de su detención. ${ }^{30}$

Pero, pese a algunas similitudes generales entre las mujeres de izquierda, también existieron diferencias entre las mujeres del PS, PC o MIR. Las mujeres del Partido Socialista o Comunista claramente tenían perfiles más públicos y reconocidos como mujeres "políticas" - a veces ejerciendo

876 Estudos Feministas, Florianópolis, 23(3): 867-892, setembro-dezembro/2015 
${ }^{31}$ La Ley 8.987, "Ley de Defensa Permanente de la Democracia" (llamada popularmente en Chile como "Ley Maldita"), fue pasada en septiembre 1948 por el gobierno del presidente Gabriel González Videla, del Partido Radical y último gobernante del período del Frente Popular. Fue una ley pasada en e contexto de la Guerra Fría que proscribió el Partido Comunista y clausuró sus posibilidades de participación en el escenario político chileno. Fue derogada en 1958 y el PC volvió a participar libremente en la política hasta el golpe de Estado de 1973. cargos dentro del gobierno de Allende - que las mujeres miristas, porque la misma estructura del MIR - que fue clandestino para la mayoría de su existencia - significó que la militancia de estas mujeres fuera frecuentemente clandestina también. O sea, podían participar mujeres del MIR en el gobierno de Allende -y de hecho participaron en grandes números - pero muchas no tenían el mismo perfil "público" de militancia que sus colegas socialistas y comunistas y, por tanto, a veces fueron menos "expuestas" a la represión inmediata de los primeros días después del golpe, cuando ocurrieron las detenciones políticas más masivas en Chile. Además, fue bastante común para mujeres del PS o PC ser de familias enteras de esa línea políica, con las familias comunistas siendo particularmente unidas y politizadas por las experiencias históricas de la Ley Maldita de $1948^{31}$ y los vaivenes del movimiento obrero y los sectores populares durante el siglo XX en Chile. En el contexto post-golpe, sin embargo, estas familias enteras, identificadas ahora como "indeseables", podrían ser blancos de la represión y el terror.

En el caso de las mujeres miristas, aunque éstas podían ser de familias de izquierda, no fue siempre la regla y, de hecho, fue bastante común que hubo mujeres miristas que salían de familias de clase media y media-alta, incluso del corazón del Partido Nacional (de derecha) y el Partido Demócrata Cristiano, aunque también hubo algunas de familias radicales, socialistas e, incluso, comunistas. Por lo mismo, hubo mujeres miristas que fueron más politizadas dentro de sus contextos escolares o laborales, y menos en lo familiar, aunque no siempre era así. En el caso de mujeres miristas que venían de familias latifundistas de derecha está claro que se unieron al MIR para emprender proyectos radicalmente opuestos a los de sus padres, mientras en el caso de mujeres miristas de familias campesinas y obreras podía existir una cierta cercanía ideológica entre padres e hijas. En todo caso, para las mujeres miristas de familias indiferentes u opuestas a sus posiciones políticas, era común que se iban a ir distanciando de sus entornos tradicionales de familia y amigos y que el MIR mismo se transformara en un tipo de "familia". Ahí, dentro de esta nueva "familia" política, las mujeres se desplegaban en todas las facetas de la vida, tanto personales como organizacionales. Ya que hubo una cantidad no menor de mujeres y hombres relativamente jóvenes en el MIR, también era frecuente que se formaban parejas, e incluso matrimonios con hijos, dentro del mismo grupo, ya que fue el espacio donde más pasaban su tiempo y se socializaban.

Pese a estas diferencias entre mujeres de diferentes vertientes de la izquierda en Chile, el 11 de septiembre de 1973 significó para todas ellas una gran ruptura en sus vidas 
y un giro hacia experiencias que serían, desde ese punto en adelante, marcadas por la ausencia, la violencia y el dolor. Más allá de las detenciones de ellas, sus compañeros/as de lucha, y sus familiares y parejas, también hubo un cambio brusco en términos de lo cotidiano y los valores que el nuevo régimen autoritario buscaba resaltar. Similar a otras dictaduras del Cono Sur de ese entonces, el gobierno de Pinochet fue estructurado por sobre patrones de género que valoraban el rol "tradicional" de la madre-esposa como cuidadora de las próximas generaciones, y, por tanto, del proyecto de nación. Por lo tanto, este mismo constructo discursivo conservador sobre la mujer fue llevado a la práctica dentro de la represión ejercida por los agentes del estado en distintos contextos - en la casa durante un allanamiento, en la calle durante una protesta, en la comisaría después de un arresto, o en los centros clandestinos de detención. En cada uno de estos lugares se ejercieron violencias que tomaron, en muchos casos, formas generizadas y sexualizadas. En los centros de detención, se agudizó la violencia de género ya que las mujeres fueron castigadas y torturadas no sólo por ser supuestas "guerrilleras" sino también por haber transgredido las fronteras aceptables de género y nación según el discurso dictatorial. Además, tanto para las mujeres como para los hombres, la violencia sexual fue utilizada para humillar y "quebrar" (o "ablandar") a los prisioneros dentro y fuera de la sala de tortura; en el caso de las mujeres, esta violencia fue tan común y corriente que llegó a ser considerada espantosamente "rutinaria" por las prisioneras. Necesidades cotidianas, como ir al baño o lavarse, fueron frecuentemente aprovechadas por los guardias y los soldados para cometer abusos sexuales.

Dentro de estas condiciones, en extremo represivas, también existieron instancias de resistencia, que se articulaban desde una solidaridad entre las mujeres presas o entre los presos más generalmente. Aquí, las cosas más pequeñas - una palabra susurrada, un pedazo de pan o una caricia después de una sesión de tortura - podían significar mucho para la persona que estaba ahí, atrapada dentro de un sistema carcelario que buscaba borrarle toda identidad personal y política. Como veremos, muchas mujeres recuerden una solidaridad muy fuerte expresada en torno a las mujeres más enfermas, las embarazadas y las ancianas, como también destacan estrategias colectivas concretas para la resistencia y el autocuidado. Una vez en libre plática - una vez que salieran de los centros de tortura más clandestinos - estas mujeres pudieron ampliar y profundizar sus relaciones de amistad con otras. Hablan de la organización de múltiples comités y colectivos dentro de los espacios carcelarios que buscaban mejorar la situación de las presas mujeres, 
${ }^{32}$ Las historias orales ocupadas en este texto vienen de dos lugares: el Archivo Oral del Centro de Documentación del Museo de los Derechos Humanos y la Memoria y el Archivo Oral de la Corporación Parque por la Paz-Villa Grimaldi. Como parte de los requisitos de Villa Grimaldi se incluyen las siguientes frases, estipuladas por el archivo como necesarias a la hora de publicar cualquier trabajo a futuro: "Esta investigación utilizó como fuente de información la Colección del Archivo Oral de Villa Grimaldi de la Corporación Parque por la Paz Villa Grimaldi. La autora agradece a la Corporación Parque por la Paz Villa Grimaldi el acceso a los registros de la Colección. Todos los resultados del estudio son de responsabilidad de la autora y en nada comprometen a dicha Institución". En lo personal, la autora también agradece, especialmente, la ayuda de Anahí Moya, quien está a cargo de este Archivo Oral. ${ }^{33}$ El Archivo Oral de Villa Grimald sólo permite la citación de los apellidos, y no los nombres de pila, de las mujeres entrevistadas. A final de la ponencia hay un listado con todos los apellidos de las mujeres citadas con los datos de citación de sus entrevistas, que fueron grabadas en video y que son accesible por DVD en el archivo. Otras entrevistas utilizadas del Archivo Oral del Centro de Documentación del Museo de los Derechos Humanos y la Memoria también fueron grabadas en video. Ya que todos estos testimonios fueron grabados en video previamente existen algunas ventajas y algunas desventajas. Por un lado, la autora no pudo formular sus propias preguntas ni tampoco conocer personalmente a las entrevistadas, como dentro de las otras historias orales que sí hizo para este proyecto. Pero, por otro lado, la posibilidad de revisar video tenía la ventaja de poder anotar ciertas sutilezas de voz y lenguaje corporal que tal vez podrían pasar más desapercibidas dentro de una historia oral más tradicional.

${ }^{34}$ MATAMALA, Colección Archivo

Oral de Villa Grimaldi. DVD No 72 formando espacios de "carreta común" para compartir alimentos o espacios de aprendizaje, con lecturas, debates, teatro y manualidades, que unían a muchas mujeres por períodos relativamente largos de tiempo. Incluso hubo instancias donde mujeres presas empezaban a organizar, desde la cárcel misma, las primeras denuncias de violaciones de los derechos humanos, que llegarían a su fruición una vez fuera, en COPACHI o en la Vicaríade la Solidaridad en Chile, o dentro de las redes del exilio europeo y latinoamericano.

Además, no es menor el detalle de que varias mujeres sitúan sus primeras aproximaciones al feminismo dentro del espacio de la cárcel y el exilio. Para ellas, estar presa o encontrarse en el exilio también significó tener el tiempo para analizar su militancia, su relación de pareja, y sus decisiones familiares y hubo una cantidad no menor de mujeres que empezaban a aplicarles a estos análisis una mirada feminista. Por lo mismo, es bien importante tomar en cuenta que los testimonios de las mujeres - todas recopiladas en archivos orales que se establecieron después del año $2000^{32,33}$ - reflejan estos procesos de reflexión y construcción de la memoria. Desde el presente, $y$, en muchos casos, desde una mirada informada por el feminismo, las mujeres ex presas políticas tienden a reconocer con bastante destreza los aspectos generizados y sexualizados de su paso por la prisión política. Por ejemplo, un componente importante aquí fue el "castigo" que los torturadores decían quererles infligir por haber sido militantes mujeres, y, por tanto, putas y "malas madres." Desde la perspectiva de los torturadores, además, no se entendía con cabalidad la razón por la cual las mujeres se habían metido en la política, asumiendo que tenía que ser por algún hombre. Al recordar los discursos de sus represores, muchas mujeres destacaban no sólo la crueldad, sino también su evidente machismo.

"[...]el hecho de ser mujer es aprovechado para poder eh destruirte. Por ejemplo, el hecho que nosotras fuéramos militantes fue para ellos era sinónimo, y nos decían, ustedes son putas. Ustedes están solamente por esto porque están con un hombre, entonces son iguales a las putas y no tienen...perdón y por lo tanto, ustedes merecen esto que les está pasando. ¿No? (...) Es como que ahí tú te enfrentaste a este desprecio absoluto hacia las mujeres, hasta considerarlas como inferiores a los hombres, a considerar que no tenían derecho a participar en un mundo con participación ciudadana, con participación política...ese no es tu espacio, porque no podrías haber estado en tu casa, como hacen las "buenas mujeres" (hace comillas con manos), todo eso era muy...muy fuerte, tremendamente fuerte." 34,35 
Angostura, 10 de agosto de 2009 ${ }^{35}$ Toda cursiva dentro de las citas es ocupada para señalar un énfasis puesto en la palabra por la entrevistada y que fue notada por la autora (obviamente es una observación subjetiva de la autora también).

${ }^{36}$ OJEDA, Archivos de la Memoria en Chile, Proyecto Piloto Región Bíobío. Testimonio Arinda Ojeda, casa de la entrevistada, Concepción, 19 de junio de 2013.

37 PEREZ, Colección Archivo Oral de Villa Grimaldi. DVD No 60 Santiago Centro, Santiago, 30 de marzo de 2009.

${ }^{38}$ BRITO,Colección Archivo Ora de Villa Grimaldi. DVD No 33 , Ñuñoa, Santiago, 13 de junio de 2008
"Y, por supuesto, aquí se daba, te digo, la expresión machista poh. En, en todo su esplendor. Porque a mí me pegaban, bueno me pegaban por ser mirista, me pegaban porque había dejado mi hijo botado (mirada de sorpresa hacia la cámara), me pegaban porque según ellos las miristas éramos peligrosas en la cama que con un $A K$ en la mano, eso era lo que decían. Entonces con cuanto compañero con quien te habían ubicado, era amante, o sea. Te pegaban (enumerando con los dedos de la mano izquierda, tirando cada dedo hacia abajo con mano derecha) por puta, por mala madre, por andar metida en cosas de hombres - porque eso es para los hombres no para las mujeres - (sonríe). Eso por una parte, $y$, por otra parte, porque se abusaba mucho ehhh sexualmente. ¿Ya? Desde la desnudez, porque para una mujer no es lo mismo que para un hombre, estar desnudo con los brazos abiertos, piernas abiertas, $y$ con todo eso $y$ vendada, vendada, con una almohada en la boca que te estrangula el grito, si no puedes ni gritar y que te meten electrodos por todos los orificios ahí también hay una exacerbación de la cosa sexual. $Y$ como, como utilizan eso ellos."36

En términos de lo cotidiano dentro de los centros de tortura y las prisiones, también existieron una serie de situaciones no higiénicas que se fueron transformando en torturas a pequeña escala. Por ejemplo, por un lado, existió todo lo que tenía que ver con las infecciones transmitidas sexualmente que no se podían cuidar bien y que desembocaban en problemas serios de salud.

"Yo me acuerdo que en mi caso... esta cosa de las llaves con electricidad que aplicaban al interior de la vagina y que eran las mismas llaves que le aplicaban en los anos de los compañeros o sobre sus (mira hacia abajo), sus penes. Bueno, muchas de nosotras pasamos, estábamos con metrorragia, con sangrados, con... muchas con infecciones. Yo me acuerdo que tenía una guata que parecía embarazada - y tenía mucho susto de estar embarazada porque había sido violada además - entonces... (se cambia de posición en asiento, mira a la distancia), saqué unas infecciones me acuerdo cuando estaba en incomunicado y después en libre plática eso de levantarme muchas muchas veces para ir al baño por estas infecciones urinarias. Yo recién me vine a sanar cuando salí en libertad, meses después." ${ }^{\prime 37}$

Otra situación de este tipo fue la falta de acceso al agua y a las toallas higiénicas cuando las mujeres tenían su menstruación. Algunas mujeres recordaron, patentemente, por ejemplo, el tema del olor y como los guardias las humillaban por eso, tapando las narices y diciendo cosas como "¿Cómo está la pescadería?"38 
${ }^{39}$ CASTILLO, Colección Archivo Oral de Villa Grimaldi. DVD No 159 , Peñalolén, Santiago, enero de 2012.

${ }^{40}$ MUÑOZ, Colección Archivo Oral de Villa Grimaldi. DVD No 87 Ñuñoa, Santiago, 14 de diciembre de 2009.

${ }^{41}$ BRITO, Colección Archivo Oral de Villa Grimaldi. DVD № 33, Nunñoa, Santiago, 13 de junio de 2008.
En general, hubo recuerdos muy fuertes y traumáticos sobre todo lo que tenía que ver con ir al baño, por la presencia de los guardias y la posibilidad de ser violadas. Vale recordar que este tipo de experiencias caen "fuera" de lo que tradicionalmente se concibe como "tortura" o como el espacio "explícito" de los torturadores. No obstante, son recuerdos patentes del ambiente de terror dentro de la prisión política, que resaltan la manera en que la violencia fue generizada y sexualizada de manera rutinaria.

"Al frente había un baño. Ayyy y allá me pasaron cosas terribles (frota una parte de la cabeza) es que con la tortura de allá había sufrido la desfloración. Por lo tanto, empecé a menstruar. Después me sacó en la noche un hombre oh no era terrible eso (mira hacia un lado) me sacaba en la noche y no habían...no había toalla higiénica ni ninguna de esas cosas, me pasaban paños y él me los ponía y era una cosa espantosa. Me acuerdo que un día reclamé de eso yo. Al jefe, que no sé quién era, y (...) me dijo, "No tenemos chupaca...chupasangres en el grupo" (pausa y mira al entrevistador). "No, no tenemos chupasangres en el grupo". Pero de esa vez nunca más apareció ese hombre en la noche. O sea igual algo sirvió". ${ }^{39}$

"Ir al baño, ese era otro problema. Y eso había que suplicar para poder ir, para que te sacaran ehhh y ahí estaba la solidaridad más, más, más linda. Porque siempre a uno le cedía el paso a otro para ir hasta que asumimos que mejor hacerse nomás (con gesto de resignación en hombros). Ehh porque no te iban a sacar y cuando te sacaban tenías riesgo de que te violaran, había muchos comentarios de compañeras que iban ido al baño y les habían sido violadas nada más que en el momento de ir al baño, ni siquiera dentro de un proceso de tortura. Entonces empezamos a...eso...a decir, Ok, mejor no corramos riesgo." 40

En estas dos narrativas, el espacio del baño, con la presencia de los guardias, fue considerado por las presas como sumamente peligroso. De hecho, en el caso de la segunda mujer, ella habla, incluso, de la decisión de orinar encima de sí misma en vez de acudir al baño justo por el miedo a la violación.

No obstante, aunque algunas mujeres juraban que no hubo diferencias en los malos tratos por clase, género ni etnia, otras sí recordaban algunos tratos diferenciados por clase, profesión o status marital. Por ejemplo, una que, estando embarazada, era una "señora con libreta" y no clasificada como "puta" por su clase social. ${ }^{41}$ Otra mujer, también de clase alta y de "buena familia", sentía que no sabían qué hacer con ella porque era una "buena chica", 
${ }^{42}$ ROMERO, Colección Archivo Oral de Villa Grimaldi. DVD No 21 La Reina, Santiago, 29 de febrero de 2008 . algo que ella misma intentaba ocupar para su propio bien, fingiendo no saber nada ni conocer a nadie, aunque no logró sostener esta estrategia a la larga. ${ }^{42}$ Una mujer de Puerto Montt, ya una profesora reconocida en la zona y de trayectoria respetada, recordó:

"Eran de los que me servían un tecito o de los que me preguntaban cosas, decían, por ejemplo, "yo," me decían, "no entiendo como una mujer como usted, una mujer culta, ehh puede ser comunista. Porque los comunistas son todos unos tontos útiles. Los utilizan y ¿cómo usted puede caer en eso?"43

Sin embargo, es necesario señalar, que, aunque estas mujeres señalaron ciertas diferencias de trato que percibieron, de igual manera, fueron todas maltratadas y torturadas. Por ejemplo, en el último caso, esta profesora respetada fue pateada en el suelo por un guardia con tanta brutalidad que se quebraron varias costillas y su nariz, todo por ser "marxista" y porque el guardia había llegado borracho y con ganas de pegarle en la noche. La mujer de "buena familia" del párrafo anterior fue violentada sexualmente repetidas veces por un guardia de Cuatro Álamos,

"Sufríamos constantemente apremios físicos...y (jugando con aros y dedos de las manos), acosos sexuales (...) por los guardias y, específicamente, por el jefe, denominado el "Larguirucho". Y era espantoso, un asco, un asco total. Esperaba que fuera tarde y esperaba que ya estabas dentro de la cama y empezaba a abrir las puertas e iba a tocarnos y a meter la mano por debajo la cama."44

Pese al hecho que las condiciones de la tortura y la prisión políica fueron indudablemente horrorosas, las mujeres presas lograron activar redes, a veces precarias por la naturaleza de su ambiente, de solidaridad y autocuidado dentro de estos espacios. Generalmente, esto se dio entre mujeres presas, pero también hubo algunas instancias mencionadas de la bondad puntual de un par de guardias hombres, como "El Beto" o "El Mauro" (Carlos Carrasco Matus), este último un caso conocido ya que éste fue un guardia brutalmente torturado y asesinado por sus pares. Se ensañaron con él después de percatarse del hecho que "El Mauro" estaba ayudando a los presos a comunicarse con sus familias y amigos. Llama la atención la poca solidaridad de género entre las mujeres guardias o agentes del estado y las mujeres presas y, de hecho, hay varias menciones de cómo mujeres de la DINA, como Humilde Ramos o Ingrid Olderock, fueron particularmente terribles y violentas durante las sesiones de tortura. Igual rechazo provocaron las mujeres colaboradoras 
${ }^{45}$ ROMERO, Colección Archivo Oral de Villa Grimaldi. DVD № 21 La Reina, Santiago, 29 de febrero de 2008.

${ }^{46}$ TAMBLAY, Colección Archivo Oral de Villa Grimaldi. DVD No 27, La Reina, Santiago, 30 de abril de 2008.

47 HOLZAPFEL, Colección Archivo Oral de Villa Grimaldi. DVD No 94 , Santiago Centro, Santiago, 1 de septiembre de 2009 y 9 de febrero de 2010. de la DINA, como Luz Arce, Marcia Merino (la "Flaca Alejandra") y María Alicia Uribe (la "Carola"), todas mencionadas en relación a la violencia y la traición dentro de los centros de tortura.

También existió solidaridad entre hombres y mujeres presos/as, aunque no se podían ver, físicamente, con mucha frecuencia, particularmente en contextos de incomunicación. No obstante, en el último caso de la mujer que estaba siendo vejada sexualmente, con otras compañeras presas, por el "Larguirucho", por ejemplo, se formuló una estrategia de denuncia de la violencia sexual en conjunto con los presos varones. Ellas tenían que gritar y hacer escándalo con platos, servicio y barrotes para que los hombres las escucharan e hicieran lo mismo, activando, de esa manera, la respuesta de los otros guardias y la posibilidad de reclamar. Aunque esta estrategia demuestra la solidaridad de algunos hombres presos con el tema de la violencia sexual ejercida contra las mujeres presas, también evidencia los límites de la solidaridad dentro de un espacio carcelario: el "Larguirucho" simplemente terminó llevándolas a su oficina, donde las abusaba en privacidad y sin tener que temer de que se produjera un "escándalo" entre los presos. ${ }^{45}$

Más allá de la solidaridad entre hombres y mujeres presos/as, lo que más existía, y lo que más se recuerda, era la solidaridad entre mujeres, probablemente debido al hecho que en muchas instancias de la prisión política hubo una estricta separación de espacios por sexo biológico. Una mujer lo recordaba como "lo mejor del ser humano salió allí como también lo peor del ser humano," ${ }^{6}$ notando como las mujeres compartían ropa, frazadas y camas (más bien catres sin colchones) y la poca comida que recibían, al punto de convertirse en una especie de familia. Muchas recuerdan también el especial cuidado que la mujeres tenían frente a las ancianas, embarazadas y adolescentes. En particular, después de las sesiones de tortura se valoraba la solidaridad de las otras de la pieza de mujeres en Villa Grimaldi:

"En la pieza de mujeres, eh, fue bonita la solidaridad entre mujeres. Yo siempre encuentro que entre las presas hubo mucha solidaridad, mucho afecto. Cuando me traían de la pieza de tortura, siempre las compañeras al lado, hacernos cariño, a preguntar si necesitaba algo, qué me dolía, y ese efecto ese amor de unas con otras, es muy importante." 47

Esta misma mujer de la cita anterior también pasó por la Venda Sexy, un centro de tortura notoriamente conocido por sus vejaciones sexuales. Ahí, y justo por el aspecto más sexual de las torturas, las mujeres también inventaron otra estrategia de sobrevivencia y autocuidado. 
${ }^{48}$ HOLZAPFEL, Colección Archivo Oral de Villa Grimaldi. DVD No 94, Santiago Centro, Santiago, 1 de septiembre de 2009 y 9 de febrero de 2010.

${ }^{49}$ E. PEREZ, Colección Archivo Oral, Centro de Documentación, Museo de los Derechos Humanos y la Memoria Archivos de la Memoria en Chile, Proyecto Piloto Región de los Ríos y los Lagos. Testimonios de Isla Teja, con Joel Asenjo, Luis Díaz, Pedro Mella, y Edita Pérez, Cárcel de Isla Teja, Valdivia, 14 de octubre de 2011 .

${ }^{50}$ OJEDA, Archivos de la Memoria en Chile, Proyecto Piloto Región Bíobío. Testimonio Arinda Ojeda, casa de la entrevistada, Concepción, 19 de junio de 2013.
"Logramos darnos cuenta en la Venda Sexy, donde fundamentalmente (mirando hacia abajo) eran torturas sexuales, violaciones y todo eso que, que, los tipos no les gustaba eh tomar a las mujeres cuando estaban con la menstruación. Entonces, nos organizamos en la Venda que, había una compañera que estaba herida de bala entonces sacamos trapitos y ella, todavía con su sangre, les dejaba trapitos en el baño o cuando alguna compañera estaba efectivamente sangrando de la menstruación, dejaba sus trapos en el baño, escondidos en un lugar que organizamos y todas andábamos con la menstruación (sonrisa). Entonces los tipos decían, "iY esta también está con la regla!" (en voz brusca como gritando). ¿ahh? Y no estábamos con la regla, pero logramos captar... y era una forma de defendernos, de protegernos (sus ojos se ponen vidriosos) y de organizarnos."48

Al pasar a libre plática, y por ende a prisiones que podían ser de más largo tiempo, muchas mujeres también se encontraban en una situación carcelaria que ya empezaba a asumir ciertos aspectos de lo rutinario Por ejemplo, una mujer socialista que estaba en Isla Teja fuera de Valdivia, recordó:

"...momentos que pasamos gratos, con nuestras colegas, nuestras amigas, nuestras compañeras, conversando, preparando nuestras comiditas, hacíamos turnos para los aseos para... (pausa larga) preparar nuestras comidas. Éramos muy solidarias. Ayudábamos harto a nuestras compañeras, a nuestros compañeros que al frente estaban." 49

Y otra también resaltó el espacio carcelario como una oportunidad para el estudio, incluso del feminismo de ese entonces. Como dijo una mujer mirista que fue detenida en el sur a principios de los años 80 por el fracaso de la Operación Retorno:

"Y bueno lo otro era las horas de estudio individual y las horas de discusión colectiva, tanto discusión política como de los temas que empezaban a ser... algo que fue muy importante para nosotras, que fue todos los temas feministas: teoría, bueno, lo que podíamos más de la teoría. Y, además, a mí me empezó a llegar mucho material, mucho material de ese lado, del lado feminista. De Italia, me suscribieron a revistas que me llegaban, otras suscripciones que me llegaron... El Lilit, que no me acuerdo de las siglas, qué era, pero era todo un centro de estudios, también de feministas. Me llegaba mucho, mucho material. Entonces, estudiábamos. Bueno ahí en esos años me leí El Segundo Sexo de la Simone de Beauvoir (sonriendo) que no lo leía en la cárcel no lo iba a leer porque es tan grueso. Entonces había todo un trabajo digamos." ${ }^{50}$

884 Estudos Feministas, Florianópolis, 23(3): 867-892, setembro-dezembro/2015 
${ }^{51}$ ALVARADO, Colección Archivo Oral, Centro de Documentación, Museo de los Derechos Humanos y la Memoria Archivos de la Memoria en Chile, Proyecto Piloto Región de los Ríos y los Lagos. Testimonio María Irma Alvarado Barría Centro Cultural Diego Rivera Puerto Montt, 27 de marzo de 2012.
No obstante, al escuchar los testimonios de las mujeres es también importante reconocer que estos espacios carcelarios podían ser muy complejos, no sólo sitios de represión y resistencia, sino también sitios donde se podían producir tensiones entre las presas y donde el objetivo de la resistencia solidaria entre todas no fue siempre posible. A un nivel muy básico esto se podía dar, por ejemplo, entre los distintos tipos de presas, como las "políticas" y las "comunes":

"Empezamos a reclamar porque, por ejemplo, era una tortura que para efectos de las fiestas del campo que habían o las redadas de los prostíbulos llegaban estas mujeres al pabellón donde nosotros también estábamos se correteaban a cuchillo limpio con los gillete en las manos. Nosotros muchas veces teníamos que escondernos debajo las camas. Era una cosa de terror que vivíamos. Nosotros no estábamos acostumbrados a eso." 51

Pero, más allá de estas diferencias de convivencia entre las dos presas, también hubo profundas diferencias que giraban en torno al eje de delatar/no delatar. Aquí es muy difícil, desde el presente, captar todas las sutilezas de lo que estaba pasando en ese momento, particularmente porque en el presente es generalmente de acuerdo común dentro de los/as testimoniantes que hablar de los/as delatores/as es completamente tabú. Por tanto, siguen ahí, nombrados/as y no nombrados/as, hombres y mujeres sin identidad, ni tampoco pasado (las únicas excepciones son "los/as imperdonables" que pasaron al otro bando, como Luz Arce, donde sí hay denuncias constantes y claras). Ahí hay muchos códigos que seguramente sólo son descifrables entre ellos/ as, de los/as que pasaron por experiencias compartidas de la militancia y la prisión política y que salieron al otro lado para hablar con el lenguaje denso y polisémico de los sobrevivientes. Muchas mujeres, desde el presente, exhiben un alto nivel de análisis reflexivo sobre el tema, como si ya hubiesen pasado mucho tiempo analizando el fenómeno, hasta llegar a una especie de paz: que no pueden "juzgar", que hubo gente que no estaba en "condiciones", que tal vez habría sido diferente si fuese su hijo torturado frente sus ojos.

"La tortura es un instrumento bárbaro que, que puede llegar a cualquier extremo, incluso hacerte hablar ino? El, la, el desafío ahí es cuánto aguantas en esta situación. Y el cuanto aguantas tiene que ver mucho, me entiendes tú, con, con... .cuestiones que van mucho más allá de si tú eres valiente o no eres valiente ah? Tiene que ver con una cierta resistencia interna que te ha entregado la vida. Si no te la ha entregado ya es un problema muy, muy muy complicado ino? Porque de repente la gente decía que había que tener, como, firmeza ideológica (con leve sonrisa; entrevistador hace sonido como 
${ }^{52}$ BECKER, Colección Archivo Oral de Villa Grimaldi. DVD No 12 , Peñalolén, Santiago, 9 de septiembre de 2007 de no poder creer) para no caer. Pero, sobre todo, yo creo que había que tener adentro el caudal de, de seguridad en sí misma (toca su pecho con la mano izquierda) (...) Creo que es otra lección que hay que aprender, ¿no? (claro, respuesta de entrevistador) Que una cosa es que delatar por, por ....por conseguir la venia de la gente, o para ¿me entiendes tú? O para contribuir con ellos. Y otra cosa es una persona, ¿me entiendes tú? destrozándose a sí misma, tenga que decir algo de alguien sin el ánimo que lo fueran a traer ni nada sino que "sí vivía en tal parte" o qué sé yo y ahí es donde se engancha con la otra cuestión." 52

Más allá de reflexiones más actuales sobre la tortura, en la práctica, en el momento mismo de la prisión políica durante los años 70 y 80 hubo harto menos compasión respecto la entrega de información. Por más "inofensivas" que pudieran haber sido sus intenciones o por más apremios físicos y psicológicos que sufrieran, igual no se justificaba, particularmente desde las cúpulas de los partidos. O fuiste "leal", tuviste "firmeza ideológica", o fuiste traidor/a. Esto es muy complejo, porque como reconocen las mismas ex presas, al final, casi todas tuvieron que decir "algo". Forzar el/la torturado/a a delatar fue uno de los principales objetivos de la tortura: que la persona entregara un/a compañero/a del partido (y ojalá alguien de mayor rango) para así seguir la pista de la represión política. Así, y bajo los extremos apremios psicológicos y físicos de la tortura, mucha gente, eventualmente, terminó entregando alguna información, aunque fuese más o menos verdadera, más o menos útil. En el momento de hablar no hubo nunca total certeza de si lo que tú hablaste iba a tener como resultado otra detenida, torturada o desaparecida; simplemente se podía intentar minimizar los daños, pero nunca hubo certeza de nada. Si lo que tú dijiste sí resultó ser útil - o si realmente empezaste a "cantar" con la tortura, nombrando personas, lugares, fechas o lo que fuera para salvarte a ti mismo - entonces podías sufrir severas consecuencias por parte de tu partido, si no fueses expulsado de una. Una mujer del MIR, cuyo compañero también era de la organización y que fue secuestrado con ella el mismo día - ella estando embarazada - recuerda que el rechazo hacia los delatores era tan fuerte que incluso podía llegar a marcar a su familia. Al hablar de la solidaridad de las mujeres en Tres Álamos, rescató una sensación generalizada de cercanía con las otras presas pero también habló de un episodio doloroso de rechazo:

"Una sola vez nomás sufrí. Que una vez una compañera (...) dijo que no iba a cuidar el hijo de un traidor y me dio mucha pena porque yo pensaba pero qué absurdo.... ¿cómo pensar así? ¿Si qué culpa tienen las guaguas? Entonces daban ese tipo de cosas de repente

886 Estudos Feministas, Florianópolis, 23(3): 867-892, setembro-dezembro/2015 
${ }^{53}$ BRITO, Colección Archivo Oral de Villa Grimaldi. DVD No 33 Ñuñoa, Santiago, 13 de junio de 2008.

${ }^{54}$ ROMERO, Colección Archivo Oral de Villa Grimaldi. DVD No 21 , La Reina, Santiago, 29 de febrero de 2008.

55 CASTILLO, Colección Archivo Oral de Villa Grimaldi. DVD No 159 , Peñalolén, Santiago, enero de 2012. que...fue lo único traumático que viví pero no le dije nada porque en realidad (levanta hombros, mira hacia el lado) no....no era el momento de decirle nada. Ella estaba muy convencida de lo que decía." ${ }^{33}$

Esto fue lejos de ser el único caso conflictivo que se dio en Tres Álamos por las sospechas de "colaboración". De hecho, dos mujeres recuerdan la existencia de un Consejo de Ancianos del MIR que monitoreaba a los presos y juzgaba a los que delataban. Una de ellas fue considerada "bajo sospecho" por asociarse con ciertas personas, lo cual resultó en una bajada de estatus y rango dentro de la organización, y al ser reinstalada e iniciar una relación de correspondencia por carta con otro preso, que había sido quebrado por la tortura (un "mal comportamiento") el Consejo le dijo que tenía que terminar de inmediato la relación, lo cual ella hizo porque era eso o dejar de pertenecer al MIR. ${ }^{54}$ Otra mujer, del Partido Comunista, tuvo la siguiente observación sobre las mujeres miristas dentro de Tres Álamos:

"La mayor dificultad, lo más curioso y doloroso que yo vi en ese lugar fue la discrepancia que había entre las mismas miristas. (empieza a apuntar el dedo al entrevistador) Lo terrible que era salir de la DINA a caer en las manos de las compañeras, como se increpaban y se maltrataban porque "¿quién dijo? ¿a quién entregaste? este está desparecido" (con voz de interrogatorio)....Eso es pero horroroso (termina de apuntar dedo). Es una etapa adicional que le pusieron las propias detenidas en hacer un tormento de las mismas compañeras (...) Eso fue una cuestión...no sé si se conversará. Porque yo puedo decirlo que yo lo viví. No sé si las miristas son capaces de reconocer eso que encontraban un doble tormento, un doble tormento."55

En este trabajo, que forma parte de un proyecto de investigación que está en marcha sobre violencia de género en Chile, se ha tratado de visibilizar las experiencias de las mujeres presas políticas en Chile durante la dictadura, en todo su "abanico de color" como diría Calveiro, como también la manera en que el encierro y la tortura fueron tensionados por el género. A la misma vez, también es una reflexión sobre las instancias de resistencia, individual y colectiva, que lograron llevar a cabo estas mujeres, un aspecto que ha sido minimizado en la mayoría de los textos que tratan los temas de la prisión política y la tortura (con la parcial excepción de algunos textos de "denuncia" de índole más feminista). Como vimos en los testimonios de estas mujeres, se utilizaron muchas estrategias - algunas de la llamada "infrapolítica" de Scott a la hora de tratar de resistir la violencia generizada y sexualizada: la solidaridad de compartir palabras, comida y ropa con otras presas; el escape mental colectivo de leer y 
comentar textos (algunos feministas), la confección de "engaños" a la hora de compartir toallas higiénicas ensangrentadas o la comprensión de "vergüenzas" compartidas, como tener que orinarse encima para evitar las violaciones en el baño. A la misma vez, hubo estrategias de resistencia entre géneros, como cuando los hombres presos hacían ruido y reclamaban por las violencias sexuales perpetradas en contra de las presas. Pero no todo fue miel sobre hojuelas; también hubo tensiones entre presas, de clase, como cuando las mujeres más burguesas de "buena familia", las más educadas - las buenas madres "casadas con libreta" podían recibir, en algo, un trato diferenciado; también cuando las mujeres presas políticas se sentían "superiores" frente las presas comunes, que fueron retratadas, en muchos casos, como peligrosas y violentas. Además, el tema de la "firmeza ideológica" podía dividir muy fácilmente a las presas políticas, llevándolas a castigar colectivamente a ciertas mujeres delatoras, o sospechadas de serlo, tratándolas con desprecio por la mancha vergonzosa de la traición. Esto podría ser incluso un desprecio que excedía el/la preso/a en particular, extendiéndose a su pareja o familia, como vimos en el caso de una presa que se negó a cuidar el hijo de otra presa, por ser hijo de un supuesto "traidor". Por tanto, y como resultado de lo que hemos visto a lo largo de este artículo, proponemos hacer más estudios sobre la prisión política que demuestren matices en cuanto el "abanico de color" de las experiencias de las mujeres presas políticas, donde podemos rescatar tanto aspectos de sufrimiento como también de resistencia; instancias de solidaridad, pero también de soledad, tensión y rechazo.

\section{Referencias}

\section{Fuentes Primarias:}

Colección Archivo Oral de Villa Grimaldi (archivo sólo permite identificación con apellido)

- Becker, DVD No 12, Peñalolén, Santiago, 9 de septiembre de 2007

- Brito, DVD No 33, Ñuñoa, Santiago, 13 de junio de 2008

2012

- Castillo, DVD N 159, Peñalolén, Santiago, enero de

- Holzapfel, DVD No 94, Santiago Centro, Santiago, 1 de septiembre de 2009 y 9 de febrero de 2010

- Matamala, DVD No 72, Angostura, 10 de agosto de 2009

- Muñoz, DVD No 87, Ñuñoa, Santiago, 14 de diciembre de 2009

- Pérez, DVD No 60, Santiago Centro, Santiago, 30 de marzo de 2009 
- Romero, DVD N 21, La Reina, Santiago, 29 de febrero de 2008

- Tamblay, DVD № 27, La Reina, Santiago, 30 de abril de 2008

Colección Archivo Oral, Centro de Documentación, Museo de los Derechos Humanos y la Memoria Archivos de la Memoria en Chile, Proyecto Piloto Región de los Ríos y los Lagos

- Testimonio María Irma Alvarado Barría, Centro Cultural Diego Rivera, Puerto Montt, 27 de marzo de 2012

- Testimonios de Isla Teja, con Joel Asenjo, Luis Díaz, Pedro Mella, y Edita Pérez, Cárcel de Isla Teja, Valdivia, 14 de octubre de 2011

Archivos de la Memoria en Chile, Proyecto Piloto Región Bíobío - Testimonio Arinda Ojeda, casa de la entrevistada, Concepción, 19 de junio de 2013

Informe de la Comisión Nacional sobre la Tortura y la Prisión Política (Valech)

\section{Bibliografía Secundaria}

ÁLVAREZ, Victoria. "El encierro en los campos de concentración”. In: GIL, Fernanda; PITA, Valeria; INI, María Gabriela. Historia de las Mujeres en la Argentina. Tomo II, Siglo XX. Buenos Aires: Taurus/Alfaguara, 2000. p. 67-89.

ANDÚJAR, Andrea et. al. (comps.). Historia, género y política en los '70. Buenos Aires: Feminaria, 2005.

ANDÚJAR, Andrea et al. (eds.). De minifaldas, militancias y revoluciones. Buenos Aires: Ediciones Luxemburg, 2009.

ARFUCH, Leonor. Memoria y autobiografía. Buenos Aires: FCE, 2013.

BETTLEHEIM, Bruno. "Individual and Mass Behavior in Extreme Situations", Journal of Abnormal and Social Psychology, n. 38, p. 417-452, 1943.

BUNSTER, Ximena. "Surviving beyond Fear: Women and Torture in Latin America". In: NASH, June; SAFA, Helen. Women and Change in Latin America. South Hadley, MA: Bergin\&Garvey, 1985. p. 297-327.

CALVEIRO, Pilar. Poder y desaparición. Los campos de concentración en Argentina. Buenos Aires: Colihue, 2001 (1998).

CARRILLO, Edelmira; HERNÁNDEZ, Ester; VELOSO, Teresa. Los muros del silencio. Relatos de mujeres, violencias, identidades y memoria. Concepción: Ediciones Escaparate, 2012.

CORRADI, Juan; WEISS FAGEN, Jessica; GARRETÓN, Manuel Antonio (Eds.). Fear at the Edge: State Terror and Resistance in Latin America. Berkeley: University of California Press, 1992. 
CRENZEL, Emilio. La historia política del Nunca Más. La memoria de las desapariciones en la Argentina. Buenos Aires: Siglo XXI, 2008.

D’ANTONIO, Débora. "Políticas de desarticulación de la subjetividad sexual y de género practicadas en la cárcel de Villa Devoto durante la última dictadura militar argentina (1976-1983)". Estudios 25, p. 159-174, enero-junio 2011.

DIANA, Marta. Mujeres guerrilleras. Buenos Aires: Planeta, 1997.

DINGES, John. The Condor Years. How Pinochet and His Allies Brought Terrorism to Three Continents. New York: The New Press, 2004.

FANON, Frantz. Los condenados de la tierra. México D.F.: FCE, 1983 [1961].

FEIERSTEIN, Daniel Feierstein (Ed). Terrorismo de Estado y genocidio en América Latina. Buenos Aires: Prometeo, 2009.

FRANCO, Jean. Cruel Modernity. Durham: Duke University Press, 2013.

GAVIOLA, Edda; LARGO, Eliana; PALESTRO, Sandra. Una Historia Necesaria: Mujeres en Chile: 1973-1990. Santiago: Akí \& Ahora Ltda., 1994.

GRANDIN, Greg. Empire's Workshop: Latin America, the United States, and the Rise of the New Imperialism. New York: Holt Paperbacks, 2007.

GRAU, Olga; DELSING, Riet; BRITO, Eugenia; FARIAS, Alejandra Farias. Discurso, género y poder. Discursos públicos: Chile 1978-1993. Santiago: LOM/ARCIS, 1997.

HEDGEPETH, Sonja; SAIDEL, Rochelle. Sexual Violence against Jewish Women during the Holocaust. Waltham, MA: Brandeis University Press, 2010.

HILBERG, Raul. The Destruction of the European Jews. New Haven: Yale University Press, 1961.

HINER, Hillary. "Voces soterradas, violencias ignoradas: discurso, violencia política y género en los Informes Rettig y Valech". Latin American Research Review, v.44, n.3, p. 50-74, 2009.

JACOBS, Janet. Memorializing the Holocaust. Gender, Genocide and Collective Memory. New York: Palgrave MacMillan, 2010.

JANEWAY, Elizabeth. Powers of the Weak. New York: Knopf, 1980.

JELIN, Elizabeth. Los trabajos de la memoria. España: Siglo XXI, 2001.

KIRKWOOD, Julieta. Ser política en Chile: Los nudos de la sabiduría feminista. Santiago: Editorial Cuarto Propio, 1990 [1986].

KLEIN, Naomi. La doctrina del shock: el auge del capitalismo del desastre. Madrid: Paidós, 2007.

KLUBOCK, Thomas. Contested Communities: Class, Gender, and Politics in Chile's El Teniente Copper Mine, 1904-1951. Durham: Duke University Press, 1998. 
KORNBLUH, Peter. The Pinochet File. Washington D.C.: National Security Archive, 2013 [2003].

MALLON, Florencia. "Barbudos, Warriors, and Rotos. The MIR, Masculinity, and Power in the Chilean Agrarian Reform, 1965-74". IN: GUTMANN, Matthew (Ed.). Changing Men and Masculinities in Latin America. Durham: Duke University Press, 2003. p. 179-215.

MATTELART, Michele. "Chile: The Feminine Version of the Coup d'état,". IN:NASH, June; SAFA, Helen (Ed.). Sex and Class in Latin America: Women's Perspectives on Politics, Economics and the Family in the Third World. South Hadley: J.F. Bergin Publishers, 1980. p. 279-301.

MILLER, Francesca. Latin American Women and the Search for Social Justice. Hanover: University Press of New England, 1991.

OBERTI, Alejandra; BACCl, Claudia; CAPURRO, María; SKURA, Susana.Y nadie quería saber. Relatos de sobre violencia contra las mujeres en el terrorismo de Estado en Argentina. Buenos Aires: Memoria Abierta, 2012.

OBERTI, Alejandra. "Género como tecnología", Revista Ciencias Sociales, n. 83, p. 86-91, mayo 2013.

PEDRO, Joana; WOLFF, Cristina; VEIGA, Ana María. Resistências, gênero e feminismos contra as ditaduras no Cone Sul. Florianópolis: Editora Mulheres, 2011.

POWER, Margaret. La mujer de derecha. El poder femenino y la lucha contra Salvador Allende, 1964-1973. Santiago: Dibam/ Centro Barros Arana, 2009.

RICHARD, Nelly. Residuos y metáforas. Santiago: Cuarto Propio, 1998.

RICHARD, Nelly (Ed.). Políticas y estéticas de la memoria. Santiago: Cuarto Propio, 1999.

RICHARD, Nelly. Fracturas de la memoria. Arte y pensamiento crítico. Buenos Aires: Siglo XXI, 2007.

ROBLES, Víctor Hugo. Bandera Hueca. Historia del Movimiento Homosexual de Chile. Santiago: ARCIS/Cuarto Propio, 2008.

ROSEMBLATT, Karin. Gendered Compromises: Political Cultures and the State in Chile, 1920-1950. Chapel Hill: University of North Carolina Press, 2000.

SCOTT, James. Weapons of the Weak: Everyday forms of Peasant Resistance. New Haven: Yale University Press, 1986.

SHAYNE, Julie. The Revolution Question: Feminisms in EI Salvador, Chile, and Cuba.New Brunswick: Rutgers University Press, 2004.

SOKOLOFF, Natalie; DUPONT, Ida. "Domestic Violence.Examining the Intersections of Race, Class, and Gender - An Introduction". In: SOKOLOFF, Natalie (Ed.). Domestic Violence at the Margins. Readings on Race, 
Class, Gender and Culture. New Brunswick: Rutgers University Press, 2005.

STERN, Steve. The Secret History of Gender: Women, Men, and Power in late Colonial Mexico. Chapel Hill: University of North Carolina Press, 1995.

TELES, Amelinha; LEITE, Rosalina Leite. Da guerrilha à impresa feminista. São Paulo: Edición Intermeios, 2013.

THOMAS, Gwynn. Contesting Legitimacy in Chile. Familial Ideals, Citizenship, and Political Struggle, 1970-1990. University Park: Penn State University Press, 2011.

TINSMAN, Heidi. Partners in Conflict: The Politics of Gender, Sexuality, and Labor in the Chilean Agrarian Reform, 19501973.Durham: Duke University Press, 2002.

VALDÉS, Teresa. "Las mujeres y la dictadura militar en Chile." Documento de Trabajo, No. 94. Santiago: FLACSO, marzo 1987.

VALENZUELA, María Elena. Todos íbamos a ser reinas. La mujer en el Chile militar. Santiago: Ediciones Chile y AméricaCESOC/ACHIP, 1987.

VEZZETII, Hugo. Pasado y presente. Guerra, dictadura y sociedad en la Argentina. Buenos Aires: Siglo XXI, 2002.

VIDAURRAZAGA, Tamara. Mujeres en Rojo y Negro, reconstrucción de la memoria de tres mujeres miristas. Concepción: Ediciones Escaparate, 2007.

WOLFF, Cristina. "Machismo e feminismo nas trajetórias de militantes da esquerda armada no Cone Sul dos anos 1970: Um olhar do exílio", p. 31-48. In: PEDRO, Joana et al. (Comp.). Relações de poder e subjetividades. Ponta Grossa: Editora Todapalavra, 2011.

[Recebido em 16 de janeiro de 2015 e aceito para publicação em 15 de março de 2015]

\begin{abstract}
"Solidarity Between Women was Nice": Gender, Resistance and Political Prison in Chile During the Dictatorship"

Abstract: In this article we will use gender theory to analyze the oral histories of female political prisoners in Chile during the dictatorship. Of particular concern to us is the way in which these women were able to use gendered strategies of resistance and solidarity, although we recognize that these same strategies could prove to be insufficient due to the extreme nature of torture and political imprisonment itself, which promoted the instinct to survive at all costs. Finally, we also conclude that these women's memories of political prison have been deeply influenced, in many cases, by later contacts with feminism.
\end{abstract}

Key Words: Gender; Political Prison; Resistance; Memory; Feminism. 